\title{
Correction to: The Opportunity Cost of Negative Screening in Socially Responsible Investing
}

\author{
Pieter Jan Trinks ${ }^{1} \cdot$ Bert Scholtens $^{1,2}$
}

Published online: 9 November 2017

(C) Springer Science+Business Media B.V., part of Springer Nature 2017

\section{Correction to: J Bus Ethics (2017) 140:193-208 https://doi.org/10.1007/s10551-015- 2684-3}

Table 3 of Trinks, P. J., Scholtens, B., 2017. The Opportunity Cost of Negative Screening in Socially Responsible Investing. Journal of Business Ethics, 140(2), 193-208 reports the four-factor return performance of long-short sin stock portfolios and sin stock-free portfolios.

Unfortunately, an error has occurred with the construction of long-short portfolio returns as $R_{\text {long-short portfolio }}=$ $\left(R_{\text {long portfolio }}-R_{\mathrm{f}}\right)-\left(R_{\text {short portfolio }}-R_{\mathrm{f}}\right)-R_{\mathrm{f}}$, which involves an incorrect subtraction of the risk-free rate, resulting in an underestimation of the alphas.
We redid the analysis in the appropriate manner. This yields that the performance of sin stock portfolios is unaffected and included in Table 4 of the manuscript. Therefore, Table 3 is considerably shortened and is to be rectified as reported below.

This rectification implies that there is a negative but insignificant effect of screening on risk-adjusted return performance. Results for sin stock portfolios (Table 4 in the manuscript) are unaffected. Hence, opportunity costs of negative screening consist in the foregone investments in various sin stock categories that outperform other stocks on a risk-adjusted basis.

We sincerely apologize for any inconvenience caused.

The original article can be found online at https:// doi.org/10.1007/s10551-015-2684-3.

Bert Scholtens

1.j.r.scholtens@rug.nl

1 Department of Economics, Econometrics \& Finance, University of Groningen, PO Box 800, 9700 AV Groningen, The Netherlands

2 School of Management, University of Saint Andrews, Saint Andrews, Fife KY16 9RJ, Scotland, UK 
Table 3 Return performance of portfolios excluding sin stocks, 01/1991-12/2012

\begin{tabular}{lllllll}
\hline & Alpha & MktRf & SMB & HML & WML & $R^{2}$ \\
\hline Screened S\&P 500 versus unscreened S\&P 500 & & & & & \\
S\&P 500 without TotalSin-S\&P 500 & -0.0006 & $0.0441^{* * *}$ & $0.0649 * * *$ & 0.0153 & $-0.0167 * *$ & 0.1793 \\
& $(0.0004)$ & $(0.0081)$ & $(0.0130)$ & $(0.0156)$ & $(0.0078)$ \\
S\&P 500 without Triumvirate of Sin-S\&P 500 & $-0.0002^{*}$ & $0.0059 * * *$ & 0.0016 & -0.0004 & -0.0024 & 0.0464 \\
& $(0.0001)$ & $(0.0020)$ & $(0.0026)$ & $(0.0030)$ & $(0.0018)$ \\
\hline
\end{tabular}

This table shows the results from regressing the returns on portfolios with a long position in the S\&P 500 index screened for sin stocks and a corresponding short position in the unscreened S\&P 500 index on the US Carhart (1997) factors using LAD estimation. The TotalSin sample includes all the stocks involved with the fourteen controversial issues described in the data section and defined in Appendix 1. The Triumvirate of Sin refers to the companies involved in alcohol, tobacco, and gambling. Alpha is the intercept, indicating out- or underperformance relative to the unscreened S\&P 500 index. MktRf, SMB, HML, and WML are the coefficients on the S\&P 500 market portfolio and the US Size, Book-toMarket, and Momentum factors. In brackets are the standard errors obtained using the Design Bootstrap procedure with 10,000 replications

* Statistical significance at the $10 \%$ level. ** Statistical significance at the 5\% level. *** Statistical significance at the $1 \%$ level 